\title{
"CF chatters": the development of a theoretically informed physical activity intervention for youth with cystic fibrosis
}

\author{
Fiona Jasmine Moola ${ }^{1^{*}}$, Guy Edward John Faulkner², Jane Ellen Schneiderman ${ }^{3}$ \\ ${ }^{1}$ Simone de Beauvoir Institute, Concordia University; * Corresponding Author: fiona.moola@utoronto.ca \\ ${ }^{2}$ Graduate Department of Exercise Sciences, The University of Toronto, Toronto, Canada; \\ ${ }^{3}$ Department of Physiology and Experimental Medicine, Research Institute, The Hospital for Sick Children, Toronto, Canada.
}

Received 15 September 2011; revised 20 October 2011; accepted 31 October 2011.

\begin{abstract}
Despite the benefits of physical activity for youth living with cystic fibrosis (CF), the majority of patients are insufficiently active to meet physical activity recommendations. Existing physical activity interventions are atheoretical and tend to prescribe standardized exercise regimes which are often not appealing for children and compromise long term adherence. Following recent calls for counselling based physical activity approaches in the CF population, this study describes the development of a theoretically informed, parent-mediated, behavioural counselling intervention for CF youth-"CF Chatters". We first a) describe the development of a grounded theory of physical activity in youth with CF; b) explain how this theory informed the development and implementation of the CF Chatters program and c) reflect on the findings of our pilot intervention using a case study research design. CF Chatters participants demonstrated self reported increases in physical activity and quality of life. While further development and more robust objective measures are needed to extend this investigative pilot work, our findings suggest that behavioural counselling is an effective modality for enhancing physical activity participation and quality of life in this life limited group of children and youth.
\end{abstract}

Keywords: Cystic Fibrosis; Physical Activity; Children and Youth; Behavioural Intervention Development; Qualitative Research; Caregivers

\section{INTRODUCTION}

Cystic fibrosis (CF) is a fatal, autosomal recessive genetic disease that affects approximately $1 / 2500$ people. Although CF is a multi-system condition that affects the digestive and musculoskeletal systems, the primary cause of death is respiratory failure [1,2]. Advances in medicine are particularly evident in the case of CF and the prognosis has dramatically improved. For the first time in the history of CF care, the number of adults with CF exceeds that of children, and the average life expectancy is more than 38 years [3]. Physical therapy, aerosol inhalers, nutritional supplementation, pharmacology, and, in some cases, lung transplantation, comprise the backbone of CF treatment today. The objective of these palliative treatments is to attenuate lung function decline over time.

An improved prognosis and life expectancy, however, has done little to alleviate the lingering psycho-social burden of disease in CF [4]. Clinicians now encounter a group of youth who are living longer lives; albeit, lives that are compromised by significant morbidity and impaired quality of life. Patients with CF display high rates of morbidity and reduced psycho-social health. They are more likely to experience depression, anxiety, body image concerns, occupational restrictions, reduced quality of life, and poor treatment adherence [4]. In addition to considering the physical health of this population, it is important to develop interventions that enhance optimal functioning and quality of life.

\subsection{The Role of Physical Activity in CF}

There is growing attention to the role exercise might play in attenuating the progression of pulmonary disease [5]. Higher physical activity levels and peak $\mathrm{VO}_{2}$ are positively related to survival in CF [6,7]. This association between aerobic fitness and survival is perhaps the most compelling rationale for the incorporation of an active lifestyle into the care of CF patients. There may be a positive effect from exercise on pulmonary function 
by increasing aerobic and anaerobic capacity [8] and strengthening ventilatory muscles, with chronic exercise programs being associated with a slower rate of pulmonary function decline [9]. Furthermore, exercise stimulates mucus clearance [10]; by blocking the sodium channels of the respiratory epithelium, exercise also contributes to lower mucus viscosity and the easing of mucus clearance [11,12].

Conversely, inactivity in patients with CF may worsen lung disease and compromise participation in activities of daily living [13]. Chronically ill children, including those with CF, may suffer from exercise intolerancethese children have poor fitness, spend less time exercising, and are often deconditioned [14,15]. Many chronic illnesses place a greater energy demand on childrenwalking and other tasks may require more energy expenditure [15-17] — which leads to fatigue, lower physical function, and ultimately lower social participation and reduced quality of life. Accordingly, most youth with CF are less active than healthy age-matched peers and activity levels diminish further during adolescence [18]. However, there are four randomized control trials examining the physical and functional benefits associated with exercise training for CF children and these intervention studies demonstrate that aerobic and strength training can significantly improve pulmonary function, aerobic fitness, and strength [19-22].

From an intervention perspective, there are two central limitations in this research field. First, existing research adopts a conventional exercise training approach. Although hospital-based programs facilitate a high degree of patient supervision and monitoring [23], such programs may lack sensitivity to children's local environments, interests, and contexts and may not be inherently enjoyable and appealing for children. In addition, they are cost and resource intensive, and, upon termination of the program, they invariably encounter difficulties with sustainability $[22,23]$. The issue of sustainability deserves considerable attention, given that a frequently encountered problem for chronically ill patients is the deconditioning that occurs after the cessation of the structured exercise training program $[24,25]$. A complementary yet arguably more realistic approach is to encourage increases in physical activity by integrating opportunities for physical activity into daily routines. There is some evidence that habitual physical activity is positively associated with lung function $\left(\mathrm{FEV}_{1}\right)$ at least in girls with $\mathrm{CF}$ and that $\mathrm{FEV}_{1}$ is associated with long-term survival in CF [26]. Interventions aimed at increasing habitual physical activity may be more successful with respect to long term compliance compared to conventional exercise training interventions [27]. However, we are not aware of any interventions that have attempted to increase habitual physical activity among children with CF and examined whether increased physical activity is associated with improved quality of life.

Second, in reviewing the existing research, it is clear that there is no explicit theoretical approach informing the development and delivery of the described exercise intervention. That is, it is not clear how investigators intend to change the behaviour of their participants either in terms of short term adherence to a program or longer term maintenance of exercise behaviour. Theory-based physical activity interventions in the general adult population have been shown to be more effective at increasing activity than atheoretical interventions [28]. Theory also provides a roadmap to help clinicians promote behaviour change more efficiently. At the least, teaching the behavioural self regulation skills necessary for families to independently regulate physical activity behaviours and to adhere to physical activity over time is necessary [29]. To our knowledge, existing research has not explicitly engaged in this process. The development and application of a theoretical framework grounded in the realities of living with a chronic disease, such as CF, is necessary.

Before developing large scale interventions, the Medical Research Council [30] framework encourages researchers to engage in preliminary, developmental work with potential users, to ensure that interventions address areas of concern that are relevant to users. Methodological research suggests that this vital preparatory work is often overlooked [30]. Thus, this paper has three objectives. First, given the atheoretical nature of the literature, we describe the development of a grounded theory of physical activity for CF youth. Second, where grounded theories are rarely applied, we then describe the application of this theory in informing the development of a behavioural counselling program for CF youth known as "CF Chatters". Finally, drawing on a case study approach, we describe and reflect on a pilot evaluation of the program.

\section{METHODS: OVERVIEW}

We have conducted qualitative research with CF children and their parents to identify disease specific barriers and facilitators to physical activity participation [31,32]. This developmental work has allowed us to identify key barriers and facilitators of physical activity in this population, and develop a grounded theory of physical activity participation in CF youth. Using a case-study design, we then piloted an intervention based on a self-regulatory approach to behaviour change that engaged both youth and their primary caregivers. These steps are now described.

\subsection{Developing a Grounded Theory}

We conducted two qualitative studies that sought to 
examine how CF youth and their parents perceive and experience physical activity [31,32]. Informed by the grounded theory qualitative research tradition, we then conducted an in-depth qualitative analysis-or crystallization - of the findings from these two studies to create a theory of physical activity in CF. Grounded theory is a total qualitative research design that encompasses both methodology-or how knowledge about the social world should be produced, as well as methods or tools for the collection of data in the social world. Although grounded theory is a hotly debated and contentious research design, and reflects great evolution over time, it is a theory driven qualitative tradition that facilitates greater comprehension of a particular groups' social experience in naturalistic settings. As in the case of physical activity for youth with $\mathrm{CF}$, grounded theory is particularly useful for the investigation of unknown or poorly understood social experiences as they unfold in the social world [33-35].

While a detailed discussion about the grounded theory research tradition is beyond the scope of the present study, a few points related to this research tradition are important to discuss. Specifically, grounded theory relies on a process of abduction for the production of knowledge. Researchers may be theoretically sensitized to a particular area; having read literature on physical activity and CF, they do not arrive to the research field as a tabula rasa. However, despite being theoretically sensitized by the literature, the process is data driven. Thus, the analytic process remains grounded and embedded within the data itself. In this regard, novel information arises in and through the data and all interpretations are data driven and empirically supported [35].

Additionally, it is also critical to discuss the epistemological assumptions that lie at the heart of grounded theory. Although grounded theory has changed from a largely post positivist articulation, in this study, we employ Charmaz's social constructivist version of grounded theory. We acknowledge that the data analysis process is always an interpretive act, and, rather than discovering or "excavating" true facts, the findings are co-created interpretations that arise at the interface between the researchers and the participants. Thus, we concur with Charmaz's reflection on the data collection process when she states that "data do not provide a window on reality. Rather, the discovered reality arises from the interactive process and its temporal, cultural, and structural contexts" [34,35].

In developing our grounded theory of physical activity in CF, we were guided by Weed's eight principles for "full fat" grounded theory. Seeking to avoid methodological policing and fundamentalism, these criterion are not hard and fast rules. Rather, Weed's grounded theory criterion ensure that researchers employ all aspects of the GT tradition, rather than selectively "handpick." Adhering to these criteria enhances the internal micro level consistency of the study itself, as well as macro level consistency to larger bodies of knowledge [35].

Following Weed [35], first, we adopted an iterative stance toward the data collection and analysis process. Thus, data collection and analysis were not divorced from one another, and, rather, the emerging data analysis guided the data collection process. Furthermore, we employed theoretical sampling. Thus, the findings that emerged during the data analysis process were further "fleshed out," expanded, and explored during data collection. Thirdly, we strove to attain theoretical sensitivity. As such, while the researchers' bias invariably influences the analysis process, we strove to be cognizant of the assumptions that drive the investigation and remained open to new and emergent lines of inquiry. Fourth, the constant comparative method guided the data analysis process. While we did not adopt open, axial, and selective coding, a) the 30 transcribed interviews were thoroughly read multiple times both individually and across the data corpus, b) coded for relevant units of meaning that relate to physical activity in CF youth, c) sorted and collated into named conceptual themes, d) collapsed and refined into higher order concepts, and e) searched for the inter-relationship between themes. To aid the analytic process, we used memos-or notes-to assist with the coding of the data. Sixth, by being aware of how our personal biographies influence the research process itself, we adopted a self reflexive stance. Seventh, in both the children's and parents study, the collection of fresh data failed to render new theoretical insights or to expand our concepts. In this regard, the data was theoretically saturated. Eighth, while different criterion are used to ensure the micro-level internal consistency and quality of a qualitative analysis, the principles of fit, work, relevance, and modifiability guided our judgments about research quality. In this regard, the resulting theory accurately fits and describes the data. Furthermore, the theory offers explanations to problems that are observed within the research context, such as parental stress, and reflects the concerns that are relevant to the participants. Finally, the theory is modifiable and open to further extensions and insights that may be offered in the future about the data. Finally, we "thought theoretically" from the beginning of the investigation and strove to develop a parsimonious substantive grounded theory of this particular social experience [35]. In summary, we employed the grounded theory qualitative research tradition to conduct an in-depth analysis of the transcribed interview data from our children's and parents' study [31,32], and, in doing so, developed an initial conceptual framework that describes and explains how 
CF youth and their parents experience physical activity. Our theory is described and illustrated within the context of the literature (see Figure 1).

For CF youth and parents, the burden of disease was described as the most noxious barrier toward physical activity. By making participants feel unwell, symptoms such as breathlessness, fatigue, and dizziness led youth to avoid physical activity. The detrimental impact of disease symptoms on the ability to be active has been reported by other CF youth $[31,36]$, as well as youth with chronic diseases more broadly. Interventions must remain sensitive to youths' real and perceived symptoms and work toward the minimization of disease related burden. Furthermore, CF youth and parents reported low value toward physical activity. Within the context of feeling unwell-and lacking mastery experiences that confirmed feelings of success-youth gradually repartitioned their energy away from physical activity and did not define it as an important or valuable pursuit. Physical activity value shifts have been reported in youth with other chronic diseases [37,38], suggesting that such value changes may serve a self protective function that prevents further damage to self esteem losses. As such, physical activity interventions should work toward enhancing the value that youth ascribe toward physical activity itself. Parents stated that low self-efficacy for physical activity-or lacking experiences of success-was a detrimental barrier that led their children to avoid physical activity. The social environments in which children undertook physical activity, such as physical education settings or community physical activity groups, were often not self-efficacy supportive and were characterized by experiences of exclusion and hostility from healthy, able body peers. Youth often encountered bullying and discrimination on account of their non-normative embodiments. Low self-efficacy for physical activity is well documented $[37,39]$, and appears to be a generic experience that characterizes youth with chronic diseases more broadly. Interventions for this population should work toward self efficacy enhancement for physical activity.

CF youth underscored the importance of parental support for physical activity. Youth that lacked parental physical activity support lamented the absence of this important instrumental and emotional function, and wished that their parents would engage in physical activity with them. Regardless of whether they were positive or negative role models, parents also discussed the importance of parental role modeling of physical activity behaviours. While previous interventions have not engaged parents as important sources of social and emotional support for physical activity- and critical role models-literature from the field of pediatric obesity underscores parents' important role modeling function. In particular, due to the facts that a) parents are "gatekeepers" to health behaviour change who either facilitate or hinder physical activity, b) individual behaviours are strongly influenced by contextual, familial, and environmental factors, c) social modeling and observation is critical to the development of healthy behaviours in children, and d) members of the same family tend to be genetically and behaviourally similar, there are compelling rationales for the inclusion of parents in physical activity interventions [40-42]. Additionally, youth adopted different illness narratives to articulate their experience of living with CF. While some youth reported a sense of hope and resilience in which physical activity was employed as "proof" of the ability to conquer CF, others expressed an overwhelming sense of despair and hopelessness as a result of CF. Interestingly, youths' illness perspective influenced physical activity perceptions, with more hopeful youth adopting more positive evaluations of physical activity. While the relationship between illness narratives and physical activity perceptions requires future investigation, sociology of health and illness scholars have emphasized the importance of narrative and story telling in making meaning out of experience, and facilitating a sense of coherence [43]. Interventions should consider the relationship between youths' illness outlook and attitude, and work toward the facilitation of more positive ways of storying one's illness experience.

Finally, the higher order concept of "Living on the Edge of Health and Illness" within our grounded theory refers to the precarious and fragile grasp that these children and parents have on health, and the tremendous effort they demonstrate to prevent the encroachment of illness into their everyday lives. Children and parents live with a constant sense of stress and impending danger, and sources of stress include child non-adherence to treatment and living with a life shortening disease. In particular, given the life limiting nature of the disease, and the time consuming nature of treatment, CF patients and parents negotiate significant temporal losses, making them more sensitive to temporal stress and proper time use. "Living on the Edge of Health and Illness" comprises the broader context in which these families negotiate physical activity and influences the perceptions they adopt toward physical activity. It is critical for interventionists to remain sensitive and empathetic to the enduring sense of stress that these families negotiate, and understand that physical activity experiences are inseparable from health.

Grounded theories are often not applied and this is a significant limitation associated with the grounded theory approach [44]. In the following section, we describe the process by which our grounded theory - and each of the 


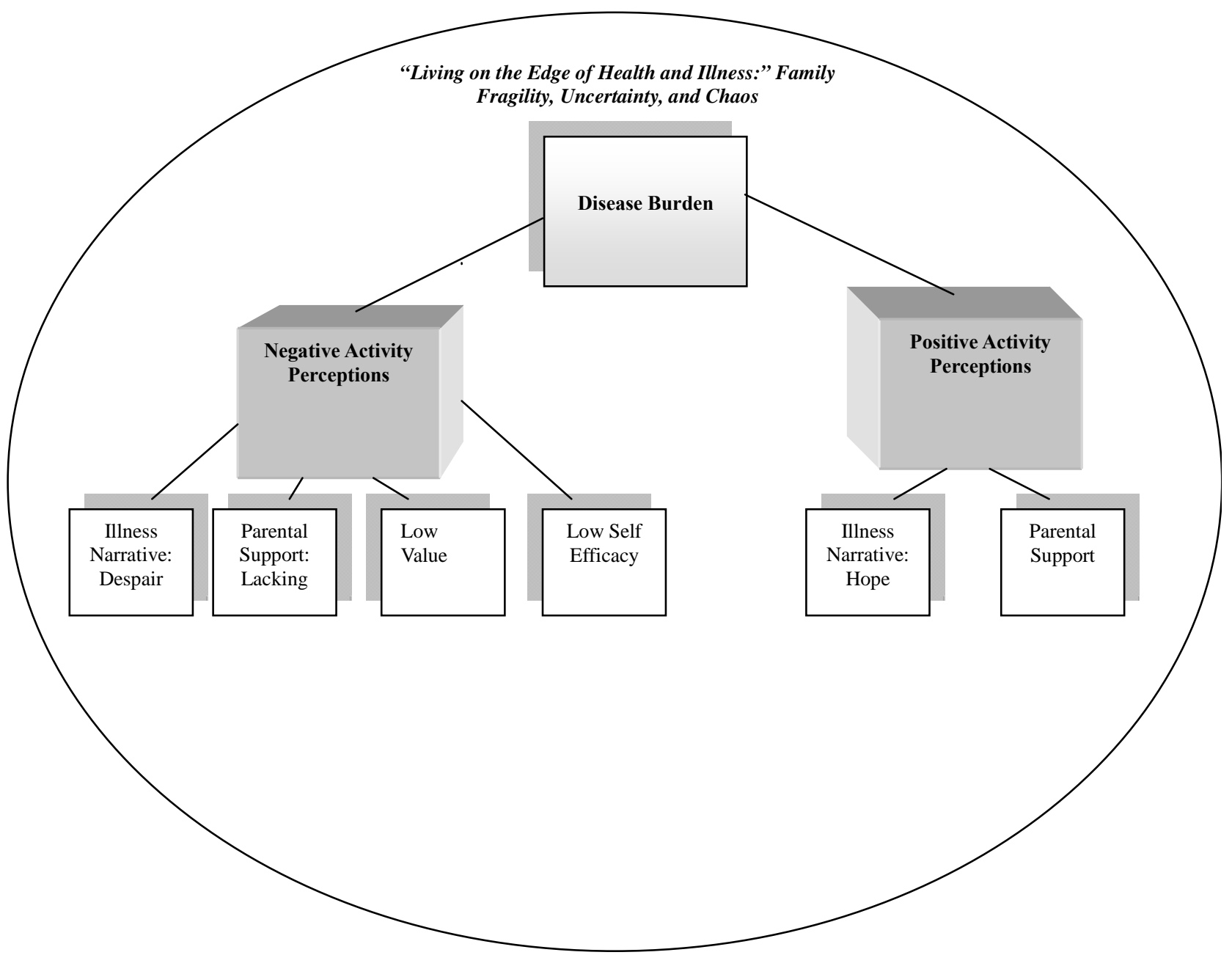

Figure 1. Toward a grounded theory of physical activity in CF.

main theoretical constructs from our theory-were applied to develop, implement, and evaluate a behavioural counselling program known as CF Chatters.

\subsection{CF Chatters-Intervention Development}

Based on this preceding work and the broader literature on the determinants of physical activity in children and youth [45], we developed a six-week family mediated physical activity counselling program called "CF Chatters". The name "CF Chatters" semantically plays on the informal, discussion based nature of the program. Since youth express negative views toward treatment, CF Chatters also demarcated the program as distinct from treatment. The content of the intervention was based upon and informed by our grounded theory which identified the disease-specific barriers and facilitators to physical activity.

The first author delivered all of the intervention content to the participants and a counselling based approach was utilized to engage the participants in informal dis- cussions. We define counselling in this context as a person and family centred consultation approach to increasing physical activity [46]. Given the limitations associated with prescribing exercise training to children and the importance of autonomy and choice to health and wellbeing, the program was based on individual activity choices. Thus, while increased physical activity was encouraged for all the participants, the exercise counsellor supported participants' autonomous decision making about enjoyable physical activities, and facilitated participant physical activity choice.

The program commenced with an initial assessment phase in which the program was explained and materials delivered. The program itself consisted of three, 90 minute counselling sessions over the course of six weeks. The length of the programme was largely driven by pragmatic concerns. We sought to develop an intervention that was effective in increasing physical activity but cost-effective in terms of the time and resources required to deliver it, and the time burden on patients. Reminder and review 
phone calls were interspersed between each session, in which the researcher phoned the participants to discuss their progress and review barriers (see Figure 2).

The session content was developed to address the central content areas from our grounded theory. For instance, workbook activities such as "My Wheel of Life" or "Where am I Going?" sought to identify and shift participants' physical activity values from our theoretical model. Session one sought to educate participants about physical activity in CF and enhance value for physical activity (Time Two). Session two sought to facilitate better temporal management of physical activity (Time Three), and session three sought to reduce barriers to physical activity participation (Time Four). In this regard, the intervention content-which was incorporated into a working manual for the participants—or homework-was embedded within our grounded theory and served as a prompt for discussion (see Table 1).

To assist in implementing the grounded theory, we were guided by Bandura's Social Cognitive Theory [47] with specific intervention components drawn from an existing taxonomy of behaviour change strategies designed to target common, hypothesized mediators of physical activity behaviour change $(48,49]$. These can be best characterized as facilitating behavioural selfregulation. Reviews of the literature on mediators of behavior change position self-regulatory constructs (e.g., planning, contingency strategies, self-monitoring) as the most consistent agents of change [50,51]. In general, health behaviour change programmes that teach behavioural skills for self-management have been recommended because of their effectiveness in promoting physical activity (Kahn et al., 2002). As described by Rhodes and colleagues [52], the basis of these approaches is that regulatory skills are required to link positive intentions to subsequent behaviour. These include, for example, the specifics of a behavioural plan (e.g., what, when, where, with who) and the problem solving and monitoring of action. Educational approaches on the benefits of physical activity for CF, and how to incorporate habitual physical activity into the day may help create positive attitudes and enhance self-efficacy. However, these approaches may not necessarily ensure positive intentions are translated into behaviour. Therefore, the intervention incorporated techniques such as goal setting, monitoring, recording, planning, and contingency planning. The goal of the intervention was to teach participants the behavioural skills required to independently manage their own physical activity, and to promote enjoyable physical activity in youths' local environments.

\subsection{CF Chatters-A Case Study Evaluation}

As "embedded case studies", [53] the CF Chatters program was pilot tested with six CF patients and their caregivers to assess the effectiveness, feasibility, and acceptability of the program. Case study research, which employs multiple methods, can be described as the indepth study and investigation of a few lives in context. The case study approach is particularly useful for preliminary intervention research in that it illuminates participants' individual uptake and appraisal of a program [53-55].

\subsection{Participants}

After approval from the Research Ethics Board at the Hospital for Sick Children, the CF Chatters intervention was delivered between September and December, 2010.

With the assistance of a clinical nurse facilitator and exercise physiologist, eligible case study participants for the CF Chatters pilot intervention were identified and contacted using the clinic data base. After the study was explained and informed and written consent obtained,

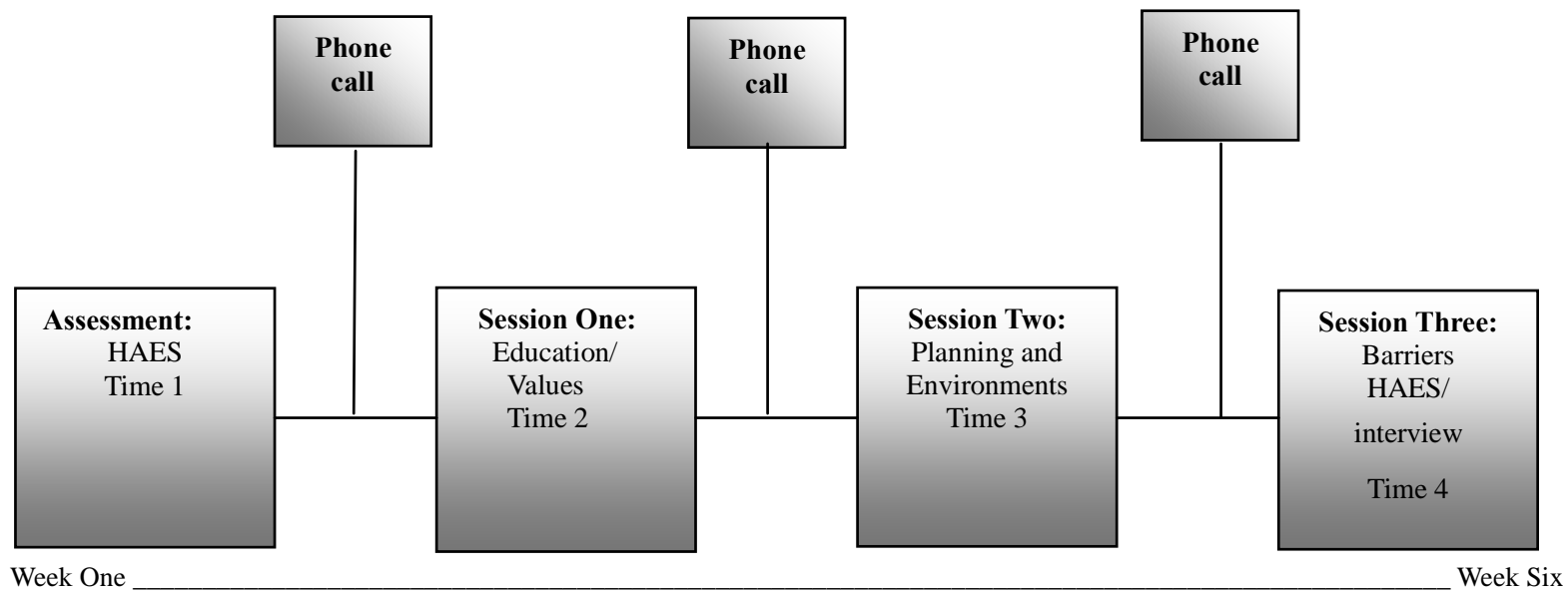

Figure 2. CF chatters program. 
Table 1. CF chatters workbook activities, theoretical constructs, and behaviour change strategy.

\begin{tabular}{|c|c|c|c|}
\hline $\begin{array}{l}\text { CF Chatters } \\
\text { Session }\end{array}$ & Work Book Activities & Theoretical Construct & $\begin{array}{c}\text { Behaviour Change Strat- } \\
\text { egy or Process }\end{array}$ \\
\hline One & $\begin{array}{l}\text {-What does PA mean to me? } \\
\text {-How does PA make me feel? } \\
\text {-What are some examples of PA's that I could engage in? } \\
\text {-What are some examples of PA's that I would really } \\
\text { enjoy engaging in? } \\
\text {-PA and the lungs } \\
\text {-What is CF? } \\
\text {-How does PA affect CF? } \\
\text {-The benefits of PA for CF } \\
\text {-The benefits of PA for overall health } \\
\text {-Other physical benefits of PA } \\
\text {-Psycho-social benefits of PA } \\
\text {-PA is safe }\end{array}$ & $\begin{array}{l}\text { Physical Activity Knowl- } \\
\text { edge }\end{array}$ & $\begin{array}{l}\text {-Psycho-Education } \\
\text {-Cognitive behavioural } \\
\text { skills } \\
\text { training (CBT) } \\
\text {-Goal setting }\end{array}$ \\
\hline One & $\begin{array}{l}\text {-What do I value in life? } \\
\text {-Where did I come from and where am I going? } \\
\text {-What are the advantages and disadvantages of } \\
\text { becoming active? }\end{array}$ & $\begin{array}{l}\text { Value Toward Physical } \\
\text { Activity }\end{array}$ & $\begin{array}{l}\text {-Psycho-Education } \\
\text {-CBT } \\
\text {-Behavioural cost and re- } \\
\text { ward } \\
\text {-Goal setting }\end{array}$ \\
\hline Two & $\begin{array}{l}\text {-What does time mean to me? How do I want } \\
\text { to use my time? } \\
\text {-Is treatment time consuming? } \\
\text {-Do I have enough time for PA? } \\
\text {-Planning PA } \\
\text {-PA Calendar activity } \\
\text {-PA action plan } \\
\text {-PA coping plan }\end{array}$ & Temporal Loses & $\begin{array}{l}\text {-Planning and Scheduling } \\
\text {-Goal setting } \\
\text {-Monitoring and recording } \\
\text {-Psycho-education } \\
\text {-CBT }\end{array}$ \\
\hline Two & $\begin{array}{l}\text {-My neighbourhood and community } \\
\text {-My PA environments } \\
\text {-How can I better engage in PA in the } \\
\text { environment? } \\
\text {-Google earth map activity }\end{array}$ & $\begin{array}{l}\text { Understanding Physical } \\
\text { Activity Environments }\end{array}$ & $\begin{array}{l}\text {-Psycho-Education } \\
\text {-CBT } \\
\text {-Mapping exercises }\end{array}$ \\
\hline Three & $\begin{array}{l}\text {-How do you feel when you are ill? } \\
\text {-What happens to your PA when you are ill? } \\
\text {-What happens to your PA when you are ill? } \\
\text {-Staying active during illness } \\
\text {-Falling off the wagon } \\
\text {-What are high risk PA situations? } \\
\text {-PA relapse prevention plan } \\
\text {-Obtaining social support } \\
\text {-My PA barriers } \\
\text {-Developing strategies to deal with barriers }\end{array}$ & Disease Burden & $\begin{array}{l}\text { Goal setting } \\
\text { Behavioural Cost and Re- } \\
\text { ward } \\
\text { Psycho Education } \\
\text { CBT }\end{array}$ \\
\hline All sessions & $\begin{array}{l}\text {-The wheel of life } \\
\text {-Caregiver health }\end{array}$ & $\begin{array}{l}\text {-Low self efficacy for } \\
\text { physical activity } \\
\text {-Parental support and role } \\
\text { modelling } \\
\text {-Stress }\end{array}$ & Psycho-Education and CBT \\
\hline
\end{tabular}

$\mathrm{PA}=$ Physical activity

eight participants enrolled in the CF Chatters program, including three parent-child dyads $(\mathrm{N}=6)$ and two adolescent participants $(\mathrm{N}=2)$. One parent-child dyad dropped out over the course of the investigation as a result of a CF related exacerbation, reflecting a study retention rate of $80 \%$. The remaining four child participants consisted of three girls and one boy and the mean age was 14 . Disease severity of the child participants was measured by forced expiratory volume in one second (FEV1) and ranged from $70 \%$ to $85 \%$, reflecting mild to moderate lung disease. Three of the four child participants had been hospitalized on numerous occasions. Additionally, one male and one female parent par- ticipated; their mean age was 44 years. Participants were from the Greater Toronto Area and surrounding region and reflected a range of ethnicities and socio-economic brackets.

\subsection{Data Collection Methods}

Case study research is composed of multiple methods and these are briefly described. Semi structured interviews were employed in order to explore participants' experiences of the program. Although a semi-structured interview guide was developed by the researcher to understand their experience of the intervention, the participants' responses drove further lines of inquiry and the 
interview proceeded in terms of a recursive conversation. Thus, the semi-structured interview provided a useful lens to understand participants' experiences of CF and physical activity and their perceptions of the program. These interviews were digitally taped and transcribed verbatim [56,57].

A detailed field note journal was used throughout the study to record, describe, and characterize participants' responses to the CF Chatter's program, institutional observations, personal reflections, and novel insights about the program. Over 150 pages of field work data was collected over the course of the CF Chatters program and observations were recorded before, during, and after each session. The field work data further corroborated the interviews and provided an excellent forum to understand the unique facets of participants' lives as well as their response to the program [58].

The Habitual Activity Estimation Scale (HAES) was employed as a self report measure of physical activity to track changes in physical activity as a result of the Chatters program [59] The HAES is a reliable and valid tool that was developed by pediatric researchers to assess level of habitual physical activity in children with chronic diseases.

\subsection{Data Analysis}

In order to analyze the case studies, first, a thematic analysis of the transcribed interview data and field diary data was generated [60]. Interview question responses, such as the program impact on physical activity and quality of life, were coded, named, and grouped into broader themes. Novel responses that were not a component of the interview guide, such as how the program facilitated "tough talks" or the psychological benefits of the program, were also named, coded, and grouped into themes. This thematic analysis of the transcribed data allowed us to understand participants overall perceptions toward the CF Chatters intervention. The HAES estimates the percentage of time that children and parents in this case, spend being a) inactive b) somewhat inactive c) somewhat active or d) active. Data was collected based on one typical weekday or weekend day and entered into a spreadsheet to calculate the percentage of the day spent in each of the four categories of activity. These values were compared from baseline to week six.

\section{RESULTS}

Eight participants enrolled in the CF Chatters program. However, after the first session, one parent-child dyad (two participants) dropped out due to a CF related exacerbation. The remaining six participants (two parentchild dyads and two adolescent participants) attended all sessions, reflecting $100 \%$ attendance. The participants also completed all of the workbook or homework activities prior to each session as instructed, and actively participated in weekly phone call sessions, reflecting good intervention compliance. The participants described the program as easy, convenient, relevant to their physical activity concerns and enjoyable, suggesting that the intervention was feasible and acceptable.

Physical Activity

Self reported physical activity levels measured by the HAES and as described in qualitative interviews increased among the majority of the participants over the course of the investigation (see Table 2).

In particular, percentage daily physical activity increased from pre to post test, as well as hours of active category physical activity. For instance, during her qualitative interview, 16 year old Layla explained that over the course of the program, she changed from a state of inactivity to engaging in three, 20 minute sessions of basketball/week as well as walking to school on most days of the week:

My activity did change. Now, whenever I am sitting around and doing nothing, I am starting to think that "maybe I could go aside and run around or play basketball or soccer.” It gets you active and it also helps your body.

In addition to self-reported increases in physical activity, there were seven themes that captured the benefits of the program for the participants.

Increases in Physical-Related Quality of Life: The participants consistently stated that the CF Chatters program facilitated enhanced quality of life in the physicaldomain; engaging in more physical activity led to con-

Table 2. Changes in physical activity as a result of the chatters intervention.

\begin{tabular}{|c|c|c|c|c|c|}
\hline Name & Age & $\begin{array}{c}\text { Pre to Post Test Change, \% Total } \\
\text { Daily Activity }\end{array}$ & $\begin{array}{c}\text { Pre to Post Test Change in } \\
\text { Hours of Daily PA }\end{array}$ & $\begin{array}{c}\text { Pre to Post Test Change, Active } \\
\text { Category }\end{array}$ & Outcome \\
\hline Layla & 16 & (2) & 1.89 hours & $\begin{array}{c}3.3 \% \\
0.8 \text { hours }\end{array}$ & $\begin{array}{l}\text { Increase } \\
\text { daily PA }\end{array}$ \\
\hline Chase & 17 & $6.6 \%$ & 1.58 hours & $\begin{array}{c}1.9 \% \\
0.46 \text { hours }\end{array}$ & $\begin{array}{l}\text { Increase } \\
\text { daily PA }\end{array}$ \\
\hline Emily & 11 & $18.5 \%$ & 4.44 hours & $\begin{array}{c}24.7 \% \\
5.93 \text { hours }\end{array}$ & $\begin{array}{l}\text { Increase } \\
\text { daily PA }\end{array}$ \\
\hline Zoe & 12 & $-7.6 \%$ & -1.83 hours & $\begin{array}{c}1.1 \% \\
0.25 \text { hours }\end{array}$ & $\begin{array}{l}\text { Decrease } \\
\text { daily PA }\end{array}$ \\
\hline
\end{tabular}

$\mathrm{PA}=$ physical activity 
sequent improvements in how they felt about their physical health and functioning. Since the program bettered youths' self reported endurance and ability to partake in activities of daily living and peer group activity, it improved their physical well-being and reduced exclusion from physical tasks that contribute toward poor perceptions of physical health. For instance, one 17 years old participant, Chase, explained that the program enhanced his running ability. Since he is less likely to be excluded from physical activities with his friends and feel "down" about himself, his physical quality of life greatly improved. Reflecting on the meaning of quality of life, Chase stated that:

My quality of life altered a little. With the runningwanting to run more and then actually changing to run more-that is only going to help. So, my quality of life did raise a little. It helped the physical part of quality of life, with endurance and being able to run more. Endurance comes up all of the time with CF. It does not have to be running. It could be who knows- whatever kind of activity. Endurance and stamina are important. I can avoid situations that bring me down, because I am not able to do something. I will be able to avoid those things with better endurance and have a better quality of life.

Enhanced Physical Activity Knowledge: The program also enhanced education and awareness about the benefits of physical activity for CF. Although participants had good knowledge about cystic fibrosis, the program facilitated specific increases in knowledge about the relationship between physical activity participation and reduced disease symptoms. Additionally, participants also learned about the psychological benefits of physical activity:

But I learned that physical activity helps your psychological-and your thinking and stuff and your lungs. And, I learned that I never knew that it could help that much, but it can (Emily, age 11).

For participants with lower levels of baseline physical activity-that is, Layla, Zoe, and Gretchen-psycho-education, or educating participants about the benefits of physical activity for CF and identifying, modifying, and challenging thought misconceptions, was the most effective technique. For instance, Layla was misinformed about physical activity and falsely believed that it was injurious to health. Indeed, while increased sputum clearance and coughing during activity is beneficial for CF patients, this may frighten or confuse misinformed youth, leading them to consider physical activity as injurious. Similarly, Zoe and Gretchen were not aware of just how important physical activity is for lung health in CF, and such psycho-educational discussions facilitated better understanding.

Enhanced Self Knowledge: Additionally, the program enhanced knowledge "about the self," equipping participants with a greater understanding of who they are as unique individuals. In this regard, participants suggested that the program facilitated a greater degree of self reflexivity, awareness, and insight into personal barriers to physical activity and individual coping and resiliency:

Yes, like the questions in the book make you think about things and the kind of person that you are. Well, the program has made me think more about myself, and to think about what I need to do to stay healthy and to have a good life (Layla, age 16)

Value Shifts: The program also appeared to facilitate important value shifts in which participants came to ascribe greater value to the importance of physical activity within the context of their daily lives. Participants discussed how the program facilitated an understanding of why physical activity should be a priority and contributed toward a different perspective on the importance of physical activity:

The program gave me a different perspective. To say, "What can we do to change things and to make things a priority in all of our lives and not just their lives?” That dynamic in the family does need to shift to be more active. To becoming more of a social aspect, rather than a "oh, we have to do this, aspect ... What I got more out of it, was the change in attitude and the knowledge that there was-that we needed to have a different perspective to get active-that is what I will come away with (Gretchen, parent).

Reduced Disease Barriers: The program assisted youth in identifying and dealing with disease related barriers to physical activity. Participants devised novel coping strategies to deal with the negative impact of disease symptoms on physical activity-such as creating a relapse prevention plan-thereby arguably attenuating perceived helplessness related to inactivity. For instance, rather than remaining completely inactive when hospitalized, Emily and her parent, Erik, suggested that they could reduce the negative impact of the disease on physical activity by taking brief walks in the hospital unit or on the hospital grounds outdoors. They also appreciated a proactive approach to thinking about physical activity barrier reduction:

And even what we talked about today with the barriers ... like "here are the barriers and how can you plan to overcome the barriers?" You start to think about it before it happens. And I think that is a very good thing because then you are not caught off guard, when it does happen. I think that it was important to talk about, so, again, you can plan it out ahead of time. Get used to thinking about it, ahead of time. "Like, Emily is going into the hospital. What can I do? We can walk up the stairs, right. We can walk around" (Erik, father). 
Accordingly, contingency planning-or planning what one will do if original efforts and intentions to be active are not successful-was the most effective strategy for those participants that were experiencing greater disease symptoms and burden, such as Layla, Emily, and Erik. For instance, Emily and Erik proposed a contingency plan that consisted of attending at least one dance class a week during times of illness, rather than skipping class altogether, or assisting with household chores at home rather than remaining sedentary on the basement couch.

Tough Talks

The participants suggested that the program offered important psychological benefits by facilitating "tough talks" that would have been difficult to have in the absence of a counsellor. For instance, participants valued the opportunity to discuss the social and psychological impact of living with CF with a counsellor in a safe and supportive setting. One mother in particular commented on the absence of psychology in the care of patients with CF as a limitation of clinical practice, and the importance of adopting psychological approaches to manage the psycho-social impact of caring for a CF child:

I mean, we get familiar with the medical staff. We know the respiratory therapist, we know the nutritionist, we know the nurses, and we know the doctors. But, we do not know the psychological side of things. That is because we only see psychology unless we ask for that. If you do not have a significant issue, then, you will just coast along, as though it is just a part of your life. This is a significant issue within our lives. Not just from the kids perspective, but from our perspective as well. So, having the opportunity to talk through some of those issues-even if you say "everything is fine" or, rather "maybe we do need to talk about that, a little more" ... As a parent, we tend not to have the time to have these conversations with our children. We tend to be focused on our day to day existence. We do not have the time to have an in-depth conversation and we do not have the time to spend time together, with somebody leading the discussion. It has been excellent, from that perspective "Distinctly Different". The participants described the program as distinctly different from routine clinical appointments in that the sessions were non medical and discussion focused. They appreciated that the program did not include measures of respiratory function and other medical tests and that they were given the opportunity to engage in free and open discussions about their health, values, past, and personal beliefs. The participants expressed favourable and positive perceptions toward the distinctly different nature of the CF Chatters program:

I have never had to do this before. The program felt new. Interviewer: Did new feel good or bad? It felt good because I did not have to get any shots, and I did not have to do the breathing thing. So it was actually cool (Zoe, age 12).

They are completely different appointments. When I come here, it is very structured and pretty much the same every time. I come here, do PFT's, other tests, talk to doctors, give blood work, and then I am out. This feels different. It is like I am coming here for a meeting and it does not feel like I am here for a clinic visit. I like it. Generally, people like talking about themselves. I enjoy it. Same area of the hospital, but it feels different (Chase, age 17).

The program appeared to enhance temporal repartitioning for physical activity in which participants discussed the benefits of devoting more time toward physical activity and increased their ability to plan for physical activity in their daily lives. The program also enhanced youths' ecological acuity, or awareness of the places in their local environments that were physical activity supportive. For instance, using Google Earth maps and cognitive maps, participants identified places in the familial, school, community, and neighbourhood environment that were health and physical activity supportive.

In summary, the CF Chatters program was well attended and described as easy, convenient, relevant, and acceptable for the participants. The participants described the program as distinctly different from clinical care, and expressed favourable opinions toward the non medical, child centred, discussion oriented nature of the program. Although objective measures of physical activity were not employed, the program was associated with increases in self-reported physical activity levels and quality of life in the physical domain. In addition to increased physical activity knowledge, planning skills, and reduced physical activity barriers, the program appeared to afford therapeutic benefits to participants, reduce caregiver stress, and increase knowledge about the self and the environment.

\section{DISCUSSION}

The findings from the CF Chatters pilot case study intervention can be interpreted within the context of our grounded theory of physical activity in CF and other relevant health behavior change theories. Specifically, the intervention assisted patients and parents in diminishing barriers toward physical activity, most especially, disease related burdens. Described as the most noxious and unpleasant physical activity barrier, symptoms such as fatigue and breathlessness led youth to feel bad about themselves in physical activity, contributing toward activity avoidance. The negative impact of disease symptoms on the ability to be physically active is well documented in the literature-and the vicious, "chicken or egg” cycle of inactivity and escalating disease symptoms 
that this may contribute toward [2]. By enhancing participants' capacity to manage disease related barriers and identify and strategize ways of coping, the program diminished disease burden and perceptions of disease related helplessness. It is important to note that participants found discussions about the burden of disease to be "extremely important" and "something that you have to talk about and should not avoid"-while also "slightly upsetting”. Thus, while participants suggested that discussions about the burden of disease and its impact on physical activity were very important, such discussions must occur with the utmost sensitivity. Interventionists should follow youths' lead with respect to how much and what aspects of their disease and its impact they want to discuss.

Youth with CF and other chronically ill children are at risk of physical activity "value shifts $[37,38]$ ". Within the context of feeling unwell and lacking self efficacy enhancing mastery experiences, they shift attention away from physical activity to protect self esteem, and describe it as "not important". As described by one parent [32], such progressive repartitioning of attention away from physical activity, can, over time, lead the child to develop a set of non-active interests and pursuits. The CF Chatters program appeared to facilitate slight value shifts for the participants over the course of the program. For previously active participants, the program served to reinforce the importance of activity to their broader value system. For less active participants, such as Layla, the program fostered broader discussions about what would need to change in her life for physical activity to become more valuable. In this regard, it appears that the CF Chatters program may assist youth in better identifying and discussing the importance of physical activity to their broader value system. Future interventionists should work with youth to enhance the value and importance ascribed to this construct.

Low self efficacy for physical activity among children with chronic diseases is perhaps one of the most well documented barriers toward physical activity. Often excluded from same age peer group activity, these children lack mastery experiences in physical activity and often report negative experiences that compound self efficacy losses, such as bullying and demoralization on account of their non-normative embodiments [37]. Where good physical health, verbal persuasion and encouragement, mastery experiences, and vicarious learning are critical to the development of self efficacy [61], these youth are often deprived of the critical antecedents to healthy self efficacy formation. Although self efficacy was not a central chapter in our manual or a component of our interview guide, the CF Chatters program was broadly self efficacy supportive. By providing constant praise, en- couragement, and positive reinforcement for goal attainment, we sought to enhance children's physical activity self efficacy throughout the program. Participants either displayed enhanced physical activity self efficacy, or, rather, the ability to identify situations and contexts that were self efficacy enhancing. For instance, through discussions and counselling, Chase recognized that he does not "suck at all sports". In contrast, he recognized that while swimming and sprinting exasperate disease symptoms and make him feel badly about himself, activities such as cycling are self efficacy enhancing. In this regard, the program facilitated a more contextual conceptualization of self efficacy, rather than a static view of this construct. It appears that CF Chatters is self efficacy enhancing and future interventionists should continue to work toward buffering youths' fragile physical activity self efficacy.

While it is beyond the scope of the current paper, the attitudes that youth adopted toward their illness-and illness narratives - was a very important theoretical construct that served to demarcate and differentiate the case study participants in this pilot study. The participants who displayed narratives of hope, optimism, and resilience-or what Arthur Frank [62] terms the "overcoming, restitution narrative"-reported fewer barriers toward physical activity and greater interest in adopting a physically active lifestyle. For instance, despite the fatal nature of CF, Emily, Chase, and Zoe discussed the importance of undertaking health behaviours that would slow the progression of the disease over time, such as engaging in physiotherapy, staying active, and eating well. Evidence on the benefits only confirmed their desire to be active, and they were eager to reap the health related benefits. In stark contrast, case patient Layla described a "chaotic" illness narrative [62], emphasizing her sense of futility, hopelessness, and depression. Layla often engaged in self sabotaging behaviours; since CF is ultimately fatal, she often did not see the point in treating her illness and engaged in treatment non-adherence. It is important to note that despite her negative disease outlook, Layla did display increases in physical activity behaviour and physical quality of life that exceeded those of other participants in the program. However, it was more challenging to engage Layla in the program and encourage her to be active, and her all encompassing negative world view was a difficult mindset to engage with. While all other participants maintained physical activity after the termination of the program, Layla quickly resumed her previously inactive state and "silent treatment" mode of communicating with adults. It is important for future interventions to take stock of the ways in which the illness narratives that patients construct influence not only their understanding and coping 
with illness [63], but also, their affinity and interest in physical activity. Interventionists should listen and hear [63] youths' illness narratives, and work toward developing more positive ways of storying their health and illness experiences.

Finally, the findings from this study further extend and complicate our original theoretical construct of reduced time for physical activity, suggesting that greater theoretical and methodological attention is required. Given the life shortening nature of the disease and the time consuming nature of treatment, participants in previous studies stated that they have "no time to play" [31]. Surprisingly, in the current intervention, all participants described the program as a worthwhile time investment that should be longer in duration. It is not clear if, with counselling, the program facilitated temporal repartioning for the participants in which they came to desire spending more time engaged in activities that were perceived to be valuable. Alternatively, CF patients may be "masters of their time" who do not waste time and more carefully negotiate their temporal outputs. In any case, the CF Chatters program was not regarded as wasteful of time and was a worthwhile temporal investment. This also suggests that the intervention could be developed, perhaps with top-up sessions to reinforce behavioral skills training without overburdening participants. Although the literature has repeatedly underscored the ways in which the body, self, and relationships are profoundly changed through CF and the illness experience [64], it is critical that more research on CF youths' temporal negotiations-and the impact on physical activity-be conducted. In this regard, our theory of physical activity in CF served as a useful template for the interpretation of study findings.

Given the multiple component and multiple behaviour nature of complex interventions, the Medical Research Council [30] encourages researchers to undertake early developmental and feasibility work to explore potential users intervention needs and interests, and relevant contextual issues. Furthermore, before larger scale, cost intensive research programs are undertaken [30], exploring the feasibility and likelihood of intervention work is strongly advocated. Although RCT's serve as the "gold standard" of research based evidence, there are situations that impair their feasibility and in which common sense must guide best practice. Early developmental work to explore issues of feasibility assists researchers in assessing whether an RCT should be undertaken.

Participants suggested that the intervention was easy, convenient, enjoyable, and relevant to their physical activity concerns. By completing all the intervention workbook activities and participating in phone calls and sessions, they also displayed excellent intervention com- pliance. In addition to good clinical utility and not overburdening the clinic, the intervention appears to be acceptable and feasible for the participants. For the CF population in particular who manage an arduous treatment burden, suffer from poor physical health, and display poor long term compliance with exercise training regimes, issues of feasibility are arguably of great importance. For instance, Gruber et al. [45] note that although their daily, home based cycling program for CF youth resulted in improved physiological and psycho-social health, the program was not perceived to be acceptable or enjoyable for the participants. From our developmental qualitative pilot work, it can be concluded that our program is feasible and that an RCT can safely be undertaken. In developing such a larger scale trial, we will be able to ensure that the intervention is sensitive to the needs of this fragile population.

\section{Limitations}

There were several conceptual and pragmatic limitations associated with the CF Chatters program. Based on our grounded theory of physical activity in CF, and literature that underscores the importance of engaging parents in ill youths' physical activity [40], the program was designed as a parent mediated intervention and separate child and parent manuals were developed. Upon starting the program, however, the adolescent case patients-Chase and Layla-opted to participate without their parents. Instead, their parents facilitated transport to the counselling sessions and waited for them in the hospital cafeteria or clinic. In contrast, the child participants Emily and Zoe activity engaged in the program with their parents.

While this limitation required us to slightly modify our intervention delivery and prevented us from delivering a uniform parent mediated program to all the participants, it is instructive. While there are invariably differences between biological and developmental age, the results from our case studies suggest that younger child participants desire to engage in the program with their parents. Indeed, they found the presence of parents to be satisfying and comforting and parents are valuable sources of knowledge for information that the child may forget. In contrast, the older adolescent participants desire to participate without their parents, or rather, with the informal facilitative support of their parent. It has been suggested that the central task for adolescents is individuation from the parent and the development of an autonomous self and distinct identity [65]. Concerns related to autonomy may be particularly heightened during this fragile developmental period. As such, it is likely that future CF Chatters child participants will engage in the program with parents. In contrast, adoles- 
cents may wish to engage in the program alone and their desire for autonomy should be supported and encouraged. Interventionists may wish to provide patients with a choice of parental involvement.

Three sessions was adequate time to deliver the content and to counsel the participants to enhance their physical activity. The program is feasible, suggesting that it can easily be incorporated into clinical practice. With respect to the limitations of the intervention itself, the reminder and review phone calls home-which were interspersed between sessions-were often difficult for the researcher to conduct. Patients and parents were often not at home at the time of the phone call, and were attending other scheduled activities. This was time consuming for the researcher and required multiple phone calls home. Future interventionists should schedule a weekly reminder and review phone call to avoid this time expense. Additionally, given that the CF clinic is very busy during day time hours, sessions were scheduled in the late afternoons and evenings. Given that children did not have to miss school, parents were pleased with the time of the appointments. As well, since the program did not interfere with the clinical day time program, clinical staff was appreciative of the program time. It was also pleasant to work with the participants in a quiet setting, free of day time interruptions. Thus, future interventionists should consider CF Chatters as an afterschool or evening hospital program.

Finally, there are clear limitations associated with adopting a qualitative, descriptive approach to investigate participants' perceptions toward a physical activity program, and reliance on self report data collection tools. Such a participant centred evaluative approach is critical to ascertaining participants' perceptions toward the program and offers valuable descriptive, interpretative, and exploratory information to ensure that later interventions are grounded in the lives and experiences of potential users. However, in the absence of objective physical activity measures, and a well powered sample that is representative of the CF populace at large, the results are not generalizable beyond the study sample itself in the "classic" sense of generalizability. However, as suggested by Conrad and others [66], the findings may offer case generalizability or transferability to similar contexts, people, and places, serving as "proof of concept.” In this regard, the findings from this pilot study may account for how other CF patients resolve similar physical activity dilemmas in other contexts. Such transferability assessments should be made by readers of this work who should judge the relevance of the findings to their clinical context based on a gradient of similarity.

Guided by the MRC framework [30], the development of a CF Chatters feasibility trial is the next step. Such a feasibility trial should be characterized by a well pow- ered sample, objective measures of physical activity, and the inclusion of a usual care condition that does not receive the CF Chatters intervention. A feasibility trail will allow researchers to further address theoretical constructs within our grounded theory, and tease out mediators of physical activity behaviour change. We found that different techniques were effective for different participants. Further research is required to stipulate the self regulatory skills that are most appropriate for the CF Chatters program. Psycho-education and contingency planning was the most effective approach for our more inactive patients and parents_-Layla, Zoe, and Gretchen, and those participants that were experiencing greater disease burden-Layla and Emily. Alternatively, goal setting, planning, and recording were most effective for those already active patients and parents who were motivated to further enhance their physical activity-Chase and Erik. Future research initiatives should work towards unraveling which behavioural self regulation skills and strategies are most appropriate for the diverse participants in the program. Generating such evidence will allow researchers to assess whether a definitive RCT should be conducted, examining the effectiveness of the physical activity behavioural counselling approach for the CF population.

\section{CONCLUSIONS}

Despite the many benefits of physical activity for the CF population, many of these youth are not meeting the guidelines for physical activity for optimal growth and development. Existing intervention research is atheoretical and tends to prescribe exercise training, rather than enjoyable physical activities of one's choice. Following a recent call by Hebestreit [67] — that behavioural counselling is critical for sustained physical activity in $\mathrm{CF}$-the intervention described in this paper is timely. In addition to demonstrating the utility of the qualitative paradigm in developing conceptual models and theoretically informed behavioural interventions, the CF Chatters program facilitated increased physical activity and quality of life. Where measures of psycho-social health and quality of life have not typically been included in intervention research, enhanced physical quality of life is a particularly noteworthy finding. While further research and development is required to assess the effectiveness of CF Chatters, this study provides a useful template for the design of programs that are suitable and sensitive to the complex health and physical activity needs of this life limited population.

\section{REFERENCES}

[1] Moorcroft, A. (2004) Individualized unsupervised exer- 
cise training in adults with cystic fibrosis: A one year randomized controlled trial. Thorax, 59, 1074-1080.

doi:10.1136/thx.2003.015313

[2] Nixon, P., Orenstein, D. and Kelsey, S. (2001) Habitual physical activity in children and adolescents with cystic fibrosis. Medicine and Science in Sports and Exercise, 33, 30-35. doi:10.1097/00005768-200101000-00006

[3] Cystic Fibrosis Foundation Patient Registry: Annual Data Report (2009).

[4] Berge, J., Patteron, J., Goetz, D. and Milla, C. (2007) Gender differences in young adults' perceptions of living with cystic fibrosis during the transition to adulthood: A qualitative investigation. Family Systems \& Health, 2, 190-203. doi:10.1037/1091-7527.25.2.190

[5] Wheatley, C.M., Wilkins, B.W. and Snyder, E.M. (2011) Exercise is medicine in cystic fibrosis. Exercise Sport Science Review, 39, 155-160. doi:10.1097/JES.0b013e3182172a5a

[6] Moorcroft, A.J., Dodd, M.E. and Webb, A.K. (1997) Exercise testing and prognosis in adult cystic fibrosis. Thorax, 52, 291-293. doi:10.1136/thx.52.3.291

[7] Nixon, P.A., Orenstein, D.M., Kelsey, S. F. and Doershuk, C.F. (1992) The prognostic value of exercise testing in patients with cystic fibrosis. New England Journal of Medicine, 327, 1785-1788. doi:10.1056/NEJM199212173272504

[8] Pianosi, P., LeBlanc, J. and Almudevar, A. (2005) Peak oxygen uptake and mortality in children with cystic fibrosis. Thorax, 60, 50-54. doi:10.1136/thx.2003.008102

[9] Schneiderman-Walker, J., Pollock, S., Corey, M., Wilkes, D., Canny, G., Pedder, L., et al. (2000) A randomized controlled trial of a 3-year home exercise program in cystic fibrosis. The Journal of Pediatrics, 136, 304-310. doi:10.1067/mpd.2000.103408

[10] Williams, C.A., Benden, C., Stevens, D. and Radtke, T. (2010) Exercise training in children and adolescents with cystic fibrosis: Theory into practice. International Journal of Pediatrics, 7.

[11] Zach, M., et al. (1981) Effect of swimming on forced expiration and sputum clearance in cystic fibrosis. Lancet, 2, 1201-1203. doi:10.1016/S0140-6736(81)91440-9

[12] Hebestreit, A., Kersting, U., Basler, B., Jeschke, R. and Hebestreit, H. (2001) Exercise inhibits epithelial sodium channels in patients with cystic fibrosis. American Journal of Respiratory and Critical Care Medicine, 164, 443-446.

[13] Moran, B. (2008) Physical training in cystic fibrosis. Cochrane data base of systematic reviews, 1, 1-12.

[14] Singh-Grewal, D., Schneiderman-Walker, J., Wright, V., Bar-Or, O., Beyene, J., Selvadurai, H., et al. (2007) The effects of vigorous exercise training on physical function in children with arthritis: A randomized, controlled, single-blinded trial. Arthritis Rheumatology, 57, 1202-1210.

[15] Takken, T., Elst, E. and van der Net, J. (2005) Pathophysiological factors which determine the exercise intolerance in patients with juvenile dermatomyositis. Current Rheumatology Reviews, 1, 91-99. doi:10.2174/1573397052954235

[16] Takken, T., Spermon, N., Helders, P.J., Prakken, A.B. and Van Der Net, J. (2003) Aerobic exercise capacity in patients with juvenile dermatomyositis. Jeuvenile Rheumatology, 30, 1075-1080.
[17] Stephens, S., Feldman, B.M., Bradley, N., Schneiderman, J., Wright, V., Singh-Grewal, D., et al. (2008) Feasibility and effectiveness of an aerobic exercise program in children with fibromyalgia: Results of a randomized controlled pilot trial. Arthritis Rheumatology, 15, 1399-1406. doi:10.1002/art.24115

[18] Prasad, S. and Cerny, F. (2002) Factors that influence adherence to exercise and their effectiveness: Application to cystic fibrosis. Pediatric Pulmonology, 34, 66-72. doi:10.1002/ppul.10126

[19] Klijn, P., Oudshoorn, A., van der Ent, C., van der Net, J., Kimpen, J. and Helders, P. (2004) Effects of anaerobic training in children with cystic fibrosis: A randomized controlled study. Chest, 125, 1299-1305. doi:10.1378/chest.125.4.1299

[20] Orenstein, D., et al. (2004) Strength vs. aerobic training in children with cystic fibrosis: A randomized controlled trial. Chest, 126, 1204-1214. doi:10.1378/chest.126.4.1204

[21] Selvadurai, H., Blimkie, C., Meyers, N., Mellis, C., Cooper, P. and Van Aspersen, P. (2002) Randomized controlled study of in-hospital exercise training programs in children with cystic fibrosis. Pediatric Pulmonology, 33, 194-200. doi:10.1002/ppul.10015

[22] Schneiderman-Walker, J., Pollock, S., Corey, M., Wilkes, D., Canny, G., Pedder, L., et al. (2000) A randomized controlled trial of a 3-year home exercise program in cystic fibrosis. The Journal of Pediatrics, 136, 304-310. doi:10.1067/mpd.2000.103408

[23] Turchetta, A., Salerno, T., Lucidi, V., Libera, F., Cutrer, R. and Bush, A. (2004) Usefulness of a program of hospital-supervised physical training in patients with CF. Pediatric Pulmonology, 38, 115-118. doi:10.1002/ppul.20073

[24] Gulman, V., de Meer, K., Backel, H., Faber, J., Berger, R. and Helders, P. (1999) Outpatient exercise training in children with cystic fibrosis: Physiological effects, perceived competence, and acceptability. Pediatric Pulmonology, 28, 39-46. doi:10.1002/(SICI)1099-0496(199907)28:1<39::AID-PP UL7>3.0.CO;2-8

[25] Verschuren O., Ketelaar, M., Gorter, J.W., Helders, P.J., Uiterwaal, C.S. and Takken, T. (2007) Exercise training program in children and adolescents with cerebral palsy: a randomized controlled trial. Archives of Pediatric Adolescent Medicine, 161, 1075-1081. doi:10.1001/archpedi.161.11.1075

[26] Van Brussel, M., Takken, T., Uiterwaal, C.S., Pruijs, H.J., Van der Net, J., Helders, P.J., et al. (2008) Physical training in children with osteogenesis imperfecta. Journal of Pediatrics, 152, 111-116. doi:10.1016/j.jpeds.2007.06.029

[27] Schneiderman-Walker, J., Wilkes, D.L., Strug, L., Lands, LC., Pollock, S.L., Selvadurai, H.C., Hay, J., Coates, A.L. and Corey, M. (2005) Sex differences in habitual physical activity and lung function decline in children with cystic fibrosis. Journal of Pediatrics, 147, 321-326. doi:10.1016/j.jpeds.2005.03.043

[28] Wilkes, D.L., Schneiderman, J.E., Nguyen, T., Heale, L., Moola, F., Ratjen, F., Coates, A.L. and Wells, G.D. (2009) Exercise and physical activity in children with cystic fibrosis. Paediatric Respiratory Reviews, 10, 105-109. 
doi:10.1016/j.prrv.2009.04.001

[29] Kahn, E.B., Ramsey, L.T., Brownson, R.C., Heath, G.W., Howze, E.H., Powell, K.E., et al. (2002) The effectiveness of interventions to increase physical activity: A systematic review. American Journal of Preventative Medicine, 4, 73-107. doi:10.1016/S0749-3797(02)00434-8

[30] Rhodes, R.E. and Pfaeffli, L.A. (2009) Mediators of physical activity behaviour change among adult nonclinical populations: A review update. Annals of Behavioral Medicine, 37, S85.

[31] Medical Research Council (MRC) (2008) Developing and evaluating complex interventions: New guidance. London.

[32] Moola, F., Faulkner, G. and Schneiderman, J. "No time to play": Perceptions toward physical activity in youth with cystic fibrosis (CF). Adapted Physical Activity Quarterly, In Press.

[33] Moola, F.J., Faulkner, G., Kirsh, J.A. and Schneiderman, J. (2011) Developing exercise interventions for children with cystic fibrosis and congenital heart disease: Learning from their parents. Psychology of Sport and Exercise, 12, 599-608.doi:10.1016/j.psychsport.2011.07.001

[34] Glaser, B.G. and Strauss, A.L. (1967) The discovery of grounded theory. Aldine, Chicago.

[35] Charmaz, C. (2003) Grounded theory in the $21^{\text {st }}$ century. In: Denzin, N. and Lincoln, Y., Eds., The Landscape of Qualitative Research: Theories and Issues (2nd Edition), Sage, London, 507-530.

[36] Weed, M. (2009) Research quality considerations for grounded theory research in sport and exercise psychology. Psychology of Sport and Exercise, 10, 502-510. doi:10.1016/j.psychsport.2009.02.007

[37] Swisher, A. and Erickson, M. (2008) Perceptions of physical activity in a group of adolescents with cystic fibrosis. Cardiopulomonary Physical Therapy Journal, 19, 103-113.

[38] Moola, F., Faulkner, G., Kirsh, J. and Kilburn, J. (2008) Physical activity and sport participation in youth with congenital heart disease: Perceptions of children and parents. Adapted Physical Activity Quarterly, 25, 49-70.

[39] Lunt, D., Briffa, K. and Ramsay, J. (2003) Physical activity levels of adolescents with congenital heart disease. Australian Journal of Physiotherapy, 49, 43-50.

[40] Bar-Mor, G., Bar-Tal, Y., Krulik, T. and Zeevi, B. (2000) Self-efficacy and physical activity in adolescents with trivial, mild, or moderate congenital cardiac malformations. Cardiology in the Young, 10, 561-566. doi:10.1017/S1047951100008829

[41] Golan, M. (2006) Parents as agents of change in childhood obesity from research to practice. International Journal of Pediatric Obesity, 1, 66-76. doi:10.1080/17477160600644272

[42] Golan, M., Kaufman, V. and Shahar, D. (2006) Childhood obesity treatment: Targeting parents exclusively v. parents and children. British Journal of Nutrition, 95, 1008-1015. doi:10.1079/BJN20061757

[43] Nader, P., et al. (1989) A family approach to cardiovascular risk reduction: Results from the San Diego health project. Health Education, 16, 229-244. doi:10.1177/109019818901600207

[44] Smith, B. and Sparkes, A. (2008) Changing bodies, changing narratives and the consequences of tellability: A case study of becoming disabled through sport. Sociology of Health \& Illness, 30, 217-236. doi:10.1111/j.1467-9566.2007.01033.x

[45] ] Wilson, H. and Hutchinson, S. (1996). Methodological mistakes in grounded theory. Nursing Research, 45, 122-124.

[46] Gruber, W., Orenstein, D., Braumann, K. and Huls, G. (2008) Health-related fitness and trainability in children with cystic fibrosis. Pediatric Pulmonology, 43, 953-964. doi:10.1002/ppul.20881

[47] Loughlan, C. and Mutrie, N. (1995) Conducting an exercise consultation: Guidelines for health professionals. Journal of the Institute of Health Education, 33, 78-82.

[48] Bandura, A. (1986) Social foundations of thought and action: A social cognitive theory. Prentice Hall Inc, Englewood Cliffs.

[49] Abraham, C. and Michie, S. (2008) A taxonomy of behavior change techniques used in interventions. Health Psychology, 27, 379-387. doi:10.1037/0278-6133.27.3.379

[50] aranowski, T., Anderson, C. and Carmack, C. (1998) Mediating variable framework in physical activity interventions. How are we doing? How might we do better? American Journal of Preventative Medicine, 15, 266-297.

[51] Lewis, B.A., Marcus, B., Pate, R.R. and Dunn, A.L. (2002) Psychosocial mediators of physical activity behavior among adults and children. American Journal of Preventive Medicine, 23, 26-35. doi:10.1016/S0749-3797(02)00471-3

[52] Rhodes, R.E. and Pfaeffli, L.A. (2009) Mediators of physical activity behaviour change among adult non-clinical populations: A review update. Annals of Behavioral Medicine, 37, s85.

[53] Rhodes, R.E., Naylor, P.-J. and McKay, H.A. (2010) Pilot study of a family physical activity planning intervention among parents and their children. Journal of Behavioral Medicine, 33, 91-100. doi:10.1007/s10865-009-9237-0

[54] Stake, R. (2000) Case studies. In: Denzin, N. and Lincoln, Y., Eds., The Handbook of Qualitative Research, Sage, Thousand Oaks, 236-247.

[55] Faulkner, G. and Biddle, G. (2004) Physical activity and depression: Considering contextualityand variability. Journal of Sport and Exercise Psychology, 26, 3-18.

[56] Flyvbjerg, B. (2004) Five misunderstandings about casestudy research. In: Seale, G., Gubrium, J. and Silverman, D., Eds., Qualitative Research Practice, Sage, Thousand Oaks, 390-404. doi:10.4135/9781848608191.d33

[57] Kvale, S. (1996) Interviews: An introduction to qualitative research interviewing. Sage, Thousand Oaks.

[58] Mason, J. (2002) An introduction to qualitative researching. Sage, Thousand Oaks.

[59] Faulkner, G., and Sparkes, A. (1999) Exercise as therapy for schizophrenia: An ethnographic study. Journal of Sport and Exercise Psychology, 21, 39-51.

[60] Hay J.A. and Cairney, J. (2006). Development of the habitual activity estimation scale for clinical research: A systematic approach. Pediatric Exercise Science, 18, 193202.

[61] Braun, V. and Clarke, V. (2006) Using thematic analysis in psychology. Qualitative Research in Psychology, 3, 77-101. doi:10.1191/1478088706qp063oa

[62] Bandura, A. (1997) Self efficacy: The exercise of control. 
W.H. Freeman and Company, New York.

[63] Frank, A. (1995) The wounded storyteller: Body, illness, and ethics. The University of Chicago Press, Chicago.

[64] Smith, B. and Sparkes, A. (2008) Changing bodies, changing narratives and the consequences of tellability: A case study of becoming disabled through sport. Sociology of Health \& Illness, 30, 217-236. doi:10.1111/j.1467-9566.2007.01033.x

[65] Glasscoe, C. and Smith, J. (2008) Through a mother's lens: A qualitative analysis reveals how temporal experience shifts when a boy born preterm has cystic fibrosis. Clinical Child Psychology and Psychiatry, 13, 609-626. doi:10.1177/1359104508096772
[66] Noom, M., Dekovic, M. and Meeus, W. (1999) Autonomy, attachment and psycho-social adjustment during adolescence: A double edged sword? Journal of Adolescence, 22, 771-783. doi:10.1006/jado.1999.0269

[67] Conrad, P. (1990) Qualitative research on chronic illness: A commentary on method and conceptual development. Social Science and Medicine, 30, 1257-1263. doi:10.1016/0277-9536(90)90266-U

[68] Hebestreit, H., Kieser, S., Junge, S., Ballman, M., Habestreit, A. and Schindler, C. (2010) Long term effects of a partially supervised conditioning programme in cystic fibrosis. European Respiratory Journal, 35, 578-583. doi:10.1183/09031936.00062409 